ae en otros estados permeabilizaban el tejido social no penetraron en eUur aquí, la educación no marchó al impulso de las nuevas doctrinas económicas, el aparato escolar soportaba el peso tradicio-

aí de tres siglos anteriores que dejaron profunda huella en $1_{d}$ brmación de las mentalidades dirigentes que se tradujo siempre en el mantenimiento de la religión por la razón o por la fuerza de las armas y en el sostenimiento de una minoría de edad intelectual de ?a $\mathrm{a}^{\mathrm{TM}}$ mlnsa mayoría de los habitantes. Por esta razón ni la moderna S niTo nacientes basamentos de la modernidad echaron raices en eUur, región que fue retrasándose con relación a otros estados de los Estados Unidos de Colombia.

\section{LA INSTRUCCIÓN PÚBLICA PRIMARIA EN EL ACTUAL EJE CAFETERO A FINALES DEL SIGLO XIX}

\author{
(Estado Soberano del Cauca)
}

MARÍA MERCEDES MOLINA H Profesora de la Universidad de Caldas

\section{Introducción}

la enseñanza en las Escuelas no se limitará a la Instrucción, sino que comprenderá el desarrollo armónico de todas las facultades del alma, de los sentidos, de las fuerzas del cuerpo lj la educación moral

Rfza en RÉGIMEN ORGÁNICO de las Escuelas Públicas Primarias del Estado Soberano del Cauca, formado con base en las disposiciones vigentes, firmado por el inspector General de Instrucción Pública Primaria en el año de 1874 y que regía para poblaciones como Santa Rosa ae Cabal, Quinchía, Marsella, Pereira, Chinchiná, Villamaria, Filandia y Salento, entre otros municipios de los actuales: Caldas, Risaralda y Quindio.

Para 1 844se inicia la creación de algunas de estas localidades, peropasaria al menos una década, ${ }^{5}$ 'fi que apareciera la inquietud de hablar sobre la necesidad de formar o instituir las escuelas públicas primarias.

e la formación escolar era considerada como algo prioritario, no se veían los frutos debido ${ }^{a}$ a carencia de recursos económicos, a que las propuestas que hacían los aldeanos para formar ${ }^{a}$ niñez y a la juventud, como que el cobro del paso por los puentes fuera destinado, en 1858 - rtalecimiento de las incipientes casas o chozas donde se instruía a los pocos niños que a ellas Mían, además, aquella iniciativa, no fue apoyada por el gobierno del Estado Soberano del ${ }^{c} Q$, del cual se dependía en ese momento histórico.

Kiuy importante destacar la selección para escoger a quienes hacian de educadores, cuál era $P^{Q}$ pel del maestro, sus cualidades y el lugar destacado en la sociedad decimonónica. 
Con base en ios Reglamentos para las Escuelas Primarias, los códigos, las Ordenanzas, y $\left.\right|_{\text {os }}$ Decretos por los cuales se organizó la instrucción Pública Primaria y el Manual del Escolar apreciaremos: eí método de enseñanza; los ramos que deben enseñarse,- sobre la admisión de los alumnos; cómo se realizaban los exámenes; del uso del tiempo, los paseos; las vacaciones; ¡05 premios; los castigos o sistemas correccional; los deberes de ios directores; sus sueldos; ia/ormación de escuelas de niñas,- $y$ el papel de ¡os padres $a e$. familia, entre otras disposiciones.

Aunque jos objetivos generales de la educación casi siempre han sido los mismos, en el siglo XIX se hacia énfasis en la formación de hombres y mujeres dignos y capaces, con un sentimiento moral bastante elevado y para grabar en sus corazones los principios de piedad, justicia, respeto a la verdad, amor a su patria, humanidad y universal benevolencia, tolerancia, sobriedad, industria y frugalidad, pureza, moderación y templanza, y en general todas las virtudes que son el ornamento de la especie humana, $y$ la base sobre que reposa toda sociedad libre. Papel que debian cumplir los Directores de las Escuelas y procurar que también ío cumplieran los maestros.

Para nuestras aldeas era lo esencial, acompañado, claro está, de un aprendizaje sobre la lectura, los números, as pesas $y$ medidas, la escritura, la aritmética, la oramática de la lenoua castellana la urbanidad, la Constitución Política Nacional y la del Estado, la geografía, la moral y la religión católica, si los padres no se oponían a ello.

\section{Antecedentes}

A mediados del siglo XIX, los habitantes de Santa Rosa de Cabal se reunieron para solicitarle al Alcalde Municipal de la Villa, no sólo la necesidad de crear la escuela sino también, sugerir la forma de recaudar los fondos con el mismo fin.

En carta con fecha del 8 de febrero de 1858 se le comunicó al señor Gobernador de la Provincia del Cauca que:

Setenta i siente vecinos de este distrito deseosos de que en él se estableciera una escuela primaria para la educación de la juventud i deseando al mismo tiempo que ía contribución con que fueron gravados sus habitantes no ascendiera a una suma que pudiera perjudicarles ihacerles odiosa la residencia aquí, se resolvieron a economizarles hasta el alimento de sus familias $p^{\wedge}$ formar los fondos que unido a su trabajo personal fuera suficiente para levantar una obra que produjera una renta segura i permanente a beneficio del mismo distrito. Al efecto, todos ellos de común acuerdo i unidos con eí mayor entusiasmo al señor Cura Pbo. José Ramón $D a^{\text {ran }}$ procedió a construir eí puente de madera (pradera) sólido y con una cubierta de paja quf ${ }^{{ }^{n}}$ y existe sobre el río Otún. Concluida la obra la presentaron a la municipalidad para que $\bullet>$ estableciera allí un derecho por el pasaje cediendo los producios a beneficio de ía educación ios niños,- i que con los sobrantes que quedaran se hicieran íos demás gastos urgentes ${ }^{\wedge}$ distrito. To do se hizo con la aprobación del Señor Gobernador de ́́ Provincia Antonio Md $^{(i)}$ el pueblo disfrutará de la posesión y dominio de aquella reñía que setenta i siete pobres $\mathrm{p}$ de familia i el digno cura habrán creado í... I '

164 - Revista Historia de ía Educación Colombiana $c \mid$ tenemos en cuenta que fue en el año de 1851, cuando por la Ley ¿el 2 de junio se confirió a los Cabildos Parroquiales la facultad de rreglar lo relacionado con la instrucción primaria en el Estado Soberano del Cauca; observamos quedos años después (1853) seda narte de la instalación para una escuela de niños en el Distrito Parroquial de Santa Rosa (población más antigua del eje cafetero y perteneciera a aquel Estado), con veinticinco alumnos.

FS importante este año porque el 7 de diciembre se sanciona En el nombre de Dios, Legislador del Universo, i por autoridad del pueblo Caucano [....] la Constitución de la Provincia del Cauca con capital en Buga.

\section{Organización}

Cabe recordar que algunas poblaciones de esta zona pertenecieron a la municipalidad de Quindío, cuya capital era Cartago y que abarcaba regiones de los actuales departamentos de: Caldas, Risaralda, Quindío y Valle del Cauca.

Obviando los obstáculos y el cambio de objetivos en el uso de los dineros destinados a la instrucción, como observamos en el caso mencionado inicialmente, y cuando menos lo esperaban los habitantes de este pueblo apareció una ordenanza de la Legislatura provincial, disponiendo que los derechos /...] que se recaudaban por cuenta de los distritos, en lo necesario ingresarán oi Tesoro de la Provincia. De esta manera se privó al distrito [...ideesa pequeña i única renta que en aquel tiempo le pertenecía a su propiedad por las razones (Sic.) expresadas; ipara cumplir con la bárbara disposición i con la resolución gubernativa se remataron ios derechos referidos aportes para favor delTesoro provincial en el año próximo pasado de $1857 / \ldots \mathrm{p}$

Al año siguiente se le informó al Gobernador de la Provincia del vumdío que el edificio destinado para escuela de niños de este tnto se halla en mal estado i que por consiguiente necesita de un

${ }^{\circ}$ nto reparo para evitar su completa (destrucción?).^

\section{PRi i itantc, se creó la Ordenanza 1 ó SOBRE INSTRUCCIÓN PUBLICA}

*ARIA, la cual organizó la educación simultánea, prohibiendo el todo de enseñanza individual.

-Lpic

${ }^{1} \mathrm{r}$ f»mos o materias que debían enseñarse eran los siguientes: 
1. Lectura impresa y manuscrita

2. Escritura

3. Aritmética

4. Gramática de la lengua castellana

5. Urbanidad

6. Constitución Política Nacional y la del Estado

7. Moral

8. Religión Católica (mientras sea la dominante en el Estado, i que los padres de los alumnos no se opongan a ello), $y$

9. Geografia

La edad de los niños para iniciarse en la escuela no debía ser menor a seis años y no podían padecer ninguna enfermedad contagiosa, lo cual era acreditado por dos facultativos o peritos.

En lo relativo a los exámenes para evaluar a los alumnos, la Ordenanza, en algunos de sus artículos, que destacamos por su particularidad, reza así:

Artículo 5o. Habrá dos exámenes anuales: uno privado que tendrá lugar el día 15 de junio, i otro público que se verificará el 15 de diciembre.

Artículo 6o. La Autoridad politica superior de la Ciudad, Villa i aldea, nombrará con la debida anticipación hasta ocho examinadores que concurran al acto, i esos no podrán excusarse sin causa legal, bajo la multa de 1 a 20 pesos, que impondrá la autoridad que haga el nombramiento.

Artículo 8o. los alumnos se presentarán en el examen divididos por clases como deben estarlo en la escuela, i serán examinados uno a uno, empezando por las clases menos adelantadas.

Artículo 9o. Los examinadores calificarán el aprovechamiento de los alumnos votando por medio de bolas blancas i negras, i se darán a cada examinador cuatro de cada una. El examinador dará su voto solo con cuatro de estas piezas ya echándolas todas blancas ó todas negras, o negras ó blancas al mismo tiempo.

(Sic.) En los exámenes privados, no habrá calificación especial

Artículo 10o. Recogidos los votos se contarán, i según su resultado se calificará al examinado. El que reúna todas las bolas blancas, llevará la nota de mui bien, el que reúna tres cuartos, ] lo menos de bolas blancas, tendrá la nota de bien, el que obteniendo la mitad no akanze a reufli los tres cuartos de bolas blancas, llei'ará la de medianamente, el que no alcanze a obtener la miti de las bolas blancas, llevará la nota de mal, i el que no llegue a obtenerla cuarta parte por lo mf* de bolas blancas tendrá la nota de mui mat

Respecto a los paseos y vacaciones, la Ordenanza señala que no darán clases los sábados por la tarde, pero que el director debe say con los alumnos al campo donde practicarán gimnasia como el salto, carrera. Las vacaciones se llevarían a cabo una vez concluido el examen anual, o sea, el resto del mes de diciembre.

A los alumnos se les premiaba por las siguientes razones:

* Constante Asistencia a la Escuela

* Cumplimiento con las tareas escolares

* Notables acciones de virtud que ejecuten y que el Director tenga conocimiento.

El premio consistía en una tarjeta de cartón donde estaba escrita la palabra "Premio" con un valor de medio centavo cada una y las distribuía el Director a los alumnos que se hubieran hecho acreedores a ellas. Estas tarjetas (o premios) debían presentárselas cada mes al Director, y por cada diez se entregaban cinco centavos.

El Capítulo 7o. de la Ordenanza 16 hacía referencia al SISTEMA CORRECCIONAL para el cual se seguían los siguientes pasos:

1. Amonestación

2. Represión en presencia de los alumnos

3. Privación de paseos

4. Sujeción a permanecer arrodillado

5. Arresto

6. Pérdida de prel'ios

7. Pena de dolor (pero esta pena no se usará sino para castigar faltas mui graves, con

8. Expulsión, ésta la imponía el Director de acuerdo con el Alcalde o Regidor según fuere el caso. (Se aplicará al alumno de malas costumbres o que pervierte a los demás). ${ }^{5}$

Por la escasa población estudiantil, los Directores también hacían las veces de maestros. Debían dar lecciones de 8 a 12 de la mañana y de 2 $\wedge 5$ de la tarde, llevar un registro diario de los alumnos, habituarlos a la cortesía, al aseo, mantener el orden y la urbanidad, ser justos e ${ }^{\mathrm{lr}}$ nparciales en los castigos, inculcar amor a la religión, obediencia a la ley, respeto a los padres y a los magistrados e informar a quien gorrespondiera, de la asistencia y malas inclinaciones de los estu-

${ }^{\mathrm{L}}$ OS sueldos se les cubría con preferencia a los demás empleados Aciales y estaban exentos de contribuciones e impuestos.

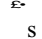

${ }^{\mathrm{s}}$ relevante comentar que en aquella época era más apreciable y ${ }^{\text {ace }}$ ptable que el Director fuera un nombre de edad avanzada. Se llegó 
a presentar el caso, donde la sociedad y/o los padres de familia protestaron porque el nombramiento había recaído en un hornbr joven, así éste llenara las condiciones morales y académicas.

Todo lo anterior -relativo a la Ordenanza 16- estaba referido a Uc escuelas para niños. Existía tratamiento diferente para las escuelas de niñas.

QUEDA ENTERADA I COMPLACIDA LA GOBERNACIÓN DEL PATRIÓTICO INTERÉS OUE TOMAN TANTO EL REJIDOR DE LA ALDEA DE CABAL, COMO LA SEÑORITA MARGARITA PORTOCARRERO POR LA INSTRUCCIÓN ; ENSEÑANZA DE LAS NIÑAS DE AQUELLA ALDEA. ${ }^{6}$

La enseñanza no era mixta y se le dio siempre prioridad a la creación de las escuelas para varones.

La legislación para las alumnas se hacía con algunas connotaciones específicas del sexo. Entre éstas se pueden mencionar las siguientes:

- La dirección, por supuesto, era ejercida por una persona del sexo femenino, ésta debía enseñar las materias que a continuación se señalan:
1. Lectura
2. Escritura
3. Aritmética
4. Gramática castellana
5. instrucción moral religiosa y urbanidad
6. Dibujo lineal
7. Geografia
8. Costura y labores propias de su sexo

- Como dato curioso no se les daba las calificaciones que menciona mos en el Artículo 10o.; sin justificar el por qué.

Las demás características se efectuaban de la misma manera para ambos sexos.

Obligaciones específicas. En este período, las multas (hasta de cuatro pesos) impuestas a los padres o personas responsables, se hacían efectivas por no enviar a sus representados puntualmente a $1^{\text {a }}$ escuela. Estas eran ejecutadas por el Jefe Municipal, Alcalde o Corregidor según el caso.

\section{Disposiciones comunes}

Articulo $3^{\circ}-L^{05}$ directores de la escuela de niños i la Directora, serán nombrados por la Corporación Municipal respectiva, i durarán por el tiempo de su buena conducta.

In Municipalidad procederá asi que esté sancionada esta Ordenanza, a hacer los nombramientos ¿e Director i Directora.'

Aunque esta legislación se observó para todo el Cauca, en la zona de presente estudio, las escuelas de niñas se establecen por lo menos diez años después de estar funcionando las de varones, (sólo existía una escuela por municipio, corregimiento o aldea).

por considerarla sumamente importante transcribimos la carta correspondiente al 29 de enero de 1869 sobre Instrucción Pública Primaria.

\section{Estados Unidos de Colombia}

\section{Estado S. del Cauca}

Al Preceptor de la escuela primaria de nifws -

Señor Alcalde Municipal de esta Villa.-

No. 1.

Paso a dar el informe que me pide por su nota de ayer, de manera siguiente:

Las materias que se enseñan en esta escuela de mi cargo son: lectura; escritura; aritméticadoctrina cristiana; gramática castellana; jeografia delpais; ortografia; dibujo lineal; constitución del estado; derecho del hombre i del ciudadano: libro de oro, moral cñstiana; historia sagradaurbanidad; citolejía; i fundamentos de la fe.

las cuatro pñmeras materias, las practican todos los alumnos de dicha escuela. los niños que estudian gramática, son diez-, jeografía, uno; ortografía, nueve; Derechos del Hombre, inieve; Libro de oro, diez, moral cñstiana, veinticuatro; urbanidad, dieziseis; citolejía, treinta; fundamentos de la fe, minr; aritmética, diez i siete; doctrina cñstiana, treinta i cinco; dibujo lineal, tres; i constitución, dos.

\section{Dejo asi satisfecha su nota antes citada. Santarosa; enero 29 de 1869.} Domingo Recio.

$£$-arta muy diciente por cuanto podemos apreciar que no todos los Alumnos de primaria tomaban las mismas materias, si eran optativas, no queda claro cuál sí era obligatorio, aunque podemos deducir, por ' número de asistentes, (35) que doctrina cristiana era la materia o bien ^ligatoria o bien la más solicitada. 
También podemos señalar que con relación al tipo de enseñanza, $1_{\mathrm{a}}$ religión (católica) tenía prioridad por encima de cualquier disciplina, pues abarcaba cuatro materias como son: moral cristiana, fundamentos de la fe, historia sagrada y doctrina cristiana.

\section{Régimen Orgánica}

Para la década de los setenta del siglo XIX rigen en el Cauca, en el campo de la organización de la Instrucción Pública, entre otras, la Ley 218 de 1867 Ley 320de 1871, varios Decretos Ejecutivos delGobierno del Estado y el Decreto nacional del lo. de noviembre de 1870, con las modificaciones introducidas por la Ley 309 de 1873 y un Convenio celebrado entre el Gobierno de la Unión y el del Estado, en ese mismo ano.

Estas nuevas disposiciones ya incluían las funciones para aquellos que dirigían la enseñanza secundaria y las escuelas normales, lo que complicó un poco la situación reinante debido a la no-claridad de las normas para su aplicación por los nuevos funcionarios.

La Escuela tenía como objetivo el de formar hombres sanos de cuerpo y espíritu, dignos y capaces de ser ciudadanos y magistrados de una sociedad republicana y libre.

Con este concepto y con la estructura curricular vigente, los niños y niñas quedaban preparados, sobre todo, para ser hombres y mujeres con unas normas y preceptos espirituales magnificados. Vimos que en cuanto al cuerpo, la educación física, corno la actual, para las décadas de los cincuenta y sesenta tenía lugar únicamente, los fines de semana, mientras que lo estrictamente académico era, prácticamente, elección voluntaria del alumno.

Este Régimen orgánico redactado en 1874 nos marca como deberá los directores de Escuela:

Hacer los mayores esfuerzos para elevar el sentimiento moral de los niños y iavenes confiado su cuidado é instrucción, y para grabar en sus corazones los principios de piedad, justicia, resp á la verdad, amará su país, humanidad]/ universal benevolencia, tolerancia, sobriedad, inda ${ }^{I} y$ frugalidad, pureza, moderación y templanza, y en general todas las virtudes que sí" ornamento de la especie humana, y la base sobre que reposa toda sociedad libre ${ }^{9}$
$\mathrm{L}_{\mathrm{a}}$ educación no se limitaba solamente al interior de la escuela sino también fuera de ella, en la única parte que no tenían autoridad era dentro de la casa paterna.

Esta costumbre se practicaba todavía en los años cincuenta del presente siglo XX, cuando los maestros salían a más de una cuadra de los planteles con el grupo escolar y muchas veces hasta entregarlos sólo a los padres. Igualmente las malas acciones cometidas por un alumno repercutían en la expulsión o en una calificación baja en conducta, lo que se traducía que al año siguiente no lo recibirían en ese plantel, y, más de las veces, se le cerraban las puertas de otros establecimientos educativos.

Los siguientes artículos del mismo régimen, por sus particularidades, sus avances respecto a normas anteriores y por sus grandes diferencias con la actualidad, vale la pena destacar. Como son:

.Artículo 6o. El Director de la Escuela deberá informarse con toda exactitud de la posición social de cada uno de sus discípulos, y de la carrera ó profesión á que se le piensa dedicar. Jales informes le servirán de base para las conferencias y consejos particulares.

Artículo 7o. La Gimnástica y Calistécnica, como parte indispensable de un sistema completo de educación, serán enseñadas en todas las Escuelas, en las horas destinadas á la recreación, según reglas sencillas y favorables al desarrollo de la salud y de las fuerzas de los niños.

Observemos que aquí ya aparecieron reglamentados otros días para la gimnasia, de acuerdo a la edad y necesidades del alumno. Asimismo, la educación religiosa pasó a otro plano sin la obligatoriedad aparente con la cual venía rigiendo y, obviamente, antes de la Constitución Política de Colombia de 1886. Miremos el siguiente artículo.

Artículo 8o. El Gobierno, en observancia del inciso 16 artículo 15 de la constitución nacional. 'io interviene en la instrucción religiosa; pero las horas de enseñanza se distribuirán dé modo que ${ }^{a}$ ws alumnos les quede tiempo suficiente para recibir tal instrucción con las mismas escuelas ó /«era de ellas, según la voluntad y por cierta de sus padres, de los preceptores que estos designen. ${ }^{\text {io }}$

pernos, entonces, que las escuelas primarias fueron divididas en: Ceméntales y superiores.

la enseñanza en las primeras, o sea las elemental, se tuvieron en cuenta la lectura, escritura, aritmética, el sistema legal de pesas y 
medidas, elementos de la lengua castellana, ejercicios de corrtposi ción y recitación, nociones generales de higiene, de geografía ${ }_{i} \wedge$ historia patria y de canto.

Para la primaria elemental ya no se hizo énfasis en la formación religiosa, pero sí se dio un lugar al sistema legal de pesas y medidas con lo cual el niño podría colaborar en las compras domésticas, pues la enseñanza debía ser práctica y no limitarse a conocimientos teóricos.

Una de las grandes diferencias con la formación actual y que es un ejemplo que se debiera seguir, lo constituye la manera de escribir, la caligrafía y que comprendía todas las reglas del arte, desde los primeros elementos de las letras hasta la escritura comente.

Para la enseñanza de las escuelas primarias superiores se tenía en cuenta las señaladas para las escuelas elementales, más las siguientes:

1. Elementos de álgebra, degeometría y sus aplicaciones usuales, especialmenteeldibujolineal. 2 Teneduría de libros, aplicada no sólo al comercio y a las oficinas públicas, sino a toda clase de cuentas.

3. Nociones de física, mecánica, química

4. Historia natural, fisiología e higiene

5. Elementos de cosmografía y geografía general, y

6. la historia y geografía especiales de Colombia.

Las anteriores materias podrían ampliarse según las necesidades locales, igualmente iniciar otras nuevas si la Dirección de Instrucción Pública consideraba pertinente.

En lo que se refería a las niñas, a éstas no se les impartían las mismas materias sino las principales -de la escuela primaria elemental ] superior- a juicio de la citada Dirección, pues debía contarse cor tiempo necesario para la enseñanza de obras de aguja, economía domést otros ejercicios que convengan particularmente a las mujeres.

Artículo 22. Es prohibido en las escuelas de niñas el hacer que éstas ejecuten labores de lujo obras de mano que en ellas se enseñen, se limitarán á la confección de piezas de vestido, en sencillas, para ambos sexos y á los más comunes y sencillos tejidos en lana y algodón.

Si el anterior artículo por sí solo nos habla de otra época, de otr« circunstancias, y merecería comentarios especiales, el Capítulo que a continuación veremos es digno de un verdadero tratado.

\section{Capítulo V}

\section{pe los Directores}

Art. 24. El Director de la Escuela, por la importancia y santidad de las funciones que ejerce, es el primer funcionario del Distñto, y tiene él deber de arreglar su conducta de manera que en su vida pública y privada sirva de tipo á todos los ciudadanos.

Arí. 25. El director debe estar sostenido y animado de un profundo sentimiento de la importancia moral de sus funciones, y fundar su principal recompensa en la satisfacción de servir á los demás hombres y de contribuir al bien público.

Art. 26. El Director de la escuela se hará amar y respetar; no solo desús discípulos, sino de toda la sociedad en que viva; será pudoroso y leal en sus relaciones, benévolo y afable en su trato, cumplido en sus maneras: pero deberá mostrar en todas ocasiones firmeza de carácterpflra hacerse obedecer y respetar. En ningún caso se dejará arrastrará accesos de pasión, ni incurrirá en otra debilidad que pueda comprometer su carácter, que debe formar un conjunto de virtudes varoniles.

Los anteriores adjetivos o cualidades que debía poseer el Director de una escuela, además de servar de ejemplo a la sociedad, nos habla de una persona muy exclusiva y con una gran trayectoria de honestidad. Quizá esto influía en no querer aceptar a jóvenes en cargos de esa categoría. Es comprensible por qué muchos de ellos dejaron una estela pedagógica, que con los años se convirtieron en personajes dignos de admiración.

Muchas de nuestras escuelas llevan su nombre Manuel S. Bmtrago, Carlota Sánchez, Deogracias Cardona, Ramón Correa Mejía, Teresa MejíaOcampo. Aquilino Bedoya y Jesús María Ornaza, por citar algunos de ellos.

$\mathrm{mi}^{1}{ }^{5}{ }^{5}$ resd ${ }_{\wedge} \tilde{n}_{\wedge \circ} 1^{\circ \mathrm{s}}$ epítetos como pundoroso, varonil, santidad, cumplido, benévolo, afable, entre otras virtudes, para hacerlas sobresalientes y equiparables.

- - Las faltas contra el pudor, la temperancia, la moderación y el aseo, así como todo abuso^ ente en su vida doméstica de la autoridad de padre, marido ó jefe de familia, serán castigados un "'ifsfro de escuela con la pérdida del empleo. 
Art. 28. El Director de la escuela procurará mantener relaciones amistosas lj benévolas con tod las personas honradas del Distrito; hablará frecuentemente con los padres de familia sobre $i$ conducta de sus hijos y les hará acerca de ellos las indicaciones convenientes. Para con los nifi ejercerá siempre una paternal solicitud; los visitará cuando estén enfermos, y si necesitan auxilio pondrá los medios para que se les proteja por las personas cañtativas.

Art. 29. Al Director de la escuela le está severamente prohibido el roce con personas reputadas o de mala conducta en el lugar, y la frecuentación de tabernas y casas de juego.

Art. 34. Ningún Director de escuela podrá, sin el permiso del Consejo administrativo, aumentar sus medios de subsistencia con el ejercicio de funciones accesoñas, ó de una profesión ú oficio cualquiera, y este permiso se rehusará siempre que el oficio ó profesión comprometa la dignidad ó moralidad del institutor, ó lo distraiga de sus funciones principales, ${ }^{11}$

Los anteriores artículos son quizá aquellos que marcan más fuertemente las diferencias de siglo y particularmente de período o época. Quizá las circunstancias demográficas, el desarrollo del capitalismo, los cambios pedagógicos, normas de conducta, alteraciones ambientales, imposición de nuevas normas educativas, aparición de elementos negativos como la droga y el mismo avance de los medios de comunicación e informática, que han influido en la vida humana, mostrándonos otras direcciones y comportamientos que han permitido cierta decadencia en la educación de los niños y niñas.

Ese Director con todos sus atributos, ejemplo y modo de ser tan peculiar, ese modelo de hombre y maestro, tenemos que rescatarlo y no permitir que pase a la historia.

En 1881, la Instrucción Pública se dividía en Primaria, Secundaria y Superior. La primera, comprendía los conocimientos elementales \}' los necesarios para adquirir, más tarde, la educación superior. Estos se daban en las escuelas elementales, superiores y normales.

La Secundaria abarcaba los ramos del saber humano, indispensables para adquirir una ciencia o ejercer una profesión científica, estudiaba en los Colegios del Estado.

Igualmente se planteaba la posibilidad de abrir escuelas o colegios por parte de particulares, acatando las normas oficiales.

En esta década y con la nueva Constitución (1886) se hacen reformas en el manejo y organización de las escuelas primarias. Una de las rnas importantes es la reglamentación de que en cada Distrito debía haber 
secciones de la mañana, y con la horizontal se señalaba la de medio día. Cuando se ha presentado la excusa (llamada licencia) por faltar a la clase, se le colocaba un punto (.) en un extremo.

Asunto de gran trascendencia histórica y que duró más de un siaío lo constituye el Capítulo X. DE LOS DEBERES RELIGIOSOS DE L ${ }^{\circ} \mathrm{OS}$ DIRECTORES Y DE LOS ALUMNOS y cuya fiel copia es como sigue:

Art. 68. La enseñanza de la Religión Católica, Apostólica, Romana es obligatoria en las Escuelas oficiales (articulo 41 de la Constitución). En tal virtud su práctica lo es igualmente para los Directores y alumnos de dichas Escuelas.

Art. 69. Es condiciónpara que un individuo sea nombrado Director o Subdirector de una Escuela el que sea católico.

Art. 70. Una vez por lo menos en el año, los alumnos de cada Escuela recibirán los Sacramentos de la Penitencia y Eucaristía i. . . ].

Art. 71. En cada Escuela se principiarán i/ concluirán [as tareas rezando en coro la oración dominical y el Ave- Maña.

Art. 72. El Director y el Subdirector, si lo hubiere, llevarán á los niños en comunidad á la misa parroquial en los días de precepto, haciéndolos guardar en el templo la debida compostura, y deberán presidirlos, de la misma manera, en cualquiera otra solemnidad religiosa á que concurran

Los anterior no necesita mucho análisis, pues es claro su contenido y su proyección en la vida política, social y cultural del país.

Para finalizar este breve camino por la instrucción pública primaria enfatizaremos en tres aspectos. Cómo se realizaban los exámenes y sus calificaciones; las escuelas de niñas, las alternadas y las rurales; $y$, sobre los períodos escolares.

Los exámenes se realizaban en los últimos días de cada período escolar, el cual iniciaba el 10 de enero y terminaba el 8 de diciembre de cada año. Aquellos tenían lugar en un edificio público si el local de la escuela no era suficiente. Previamente se fijaba en la puerta de la escuela, un aviso para comunicarlea todos los vecinos del Distrito, la hora y fecha del examen.

La calificación se hacía con números e influía la conducta que había manifestado el alumno durante el año. Se escribía con números significaban:

176 • Revista Historia de la Educación Colombian
1 Reprobado

2 Apenas aprobado

3 Aprobado

4. Notable

5. Sobresaliente

$\mathrm{p}_{\mathrm{ar}} \mathrm{a}$ las escuelas de niñas se exceptuaba la clase de Agricultura, pero cambio se daba costura, bordados y tejidos y, donde era posible, el corte de trajes.

Ají 87. En caso de que i.. . i se establezcan en algunos Distritos Escuelas alternadas, se tendrá cu cuenta lo siguiente:

I Jamás asistirán niños á las lecciones dadas á las niñas, ni al contrario,

2. Las horas de salida de los niños no coincidirán con las de entrada de las niñas lj viceversa;

3. La Directora encargará al Agente de Policía i. . I que cuide esmeradamente de que los niños

y las niñas de la Escuela no anden juntos por la calle $i . . .1$

Se tuvieron en cuenta otros elementos como los niños del campo, a quienes la distancia les impedía asistir a las escuelas urbanas. Una educación más limitada, pero se sentaron los principios para que ésta parte de la sociedad recibiera alguna instrucción.

Art. 89. En las Escuelas rurales se enseñarán estas materias: Lectura, Escritura, Aritmética, Nociones de Agricultura lj Religión.

Art. 93. fuera del mes de diciembre, los domingos, el 20 de julio, el 7 de agosto y los días festivos según el rito católico, no habrá más días de vacaciones en las Escuelas Primarias. Art. 94. Cada quince días el Director sacará á los niños á paseo. '-

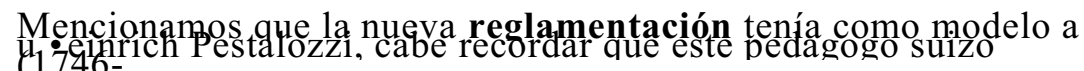

827) dedicó su vida a crear y dirigir escuelas para niños pobres en la zona rural. Planteaba que:

Lfl educación debe proporcionar los conocimientos indispensables para un oficio, de ia! suerte que preparen a la persona "por la vida para la vida" ${ }^{13}$ 


\section{Citas Bibliográficas}

1 Documentos Manuscritos, 1858. Archivo Histórico de Santa Rosa de Cabal, Risaralda Ibid.

1 Documentos .Manuscritos, 2 marzo de 1858. Archivo Histórico Santa Rosa de Cabal Risaralda.

4 Ordenanza 16 sobre Instrucción Pública Primaria, Documento Manuscrito, enero $\backslash_{i}$ ¿P 1865. Archivo Histórico de Santa Rosa de Cabal

5 Ibid.

${ }^{6}$ Carta de la Jefatura Política del Cantón. Cartago 5 de mano de 1850

- Ordenanza 16, Ob. Cit., página 5.

${ }^{8}$ El Escolar, Número extraordinario. Imprenta del Estado, 1874, página 4.

- Ibid., página $8^{10}$ Ibid., Página 15

" Reglamento para las Escudas Primarias, 1886, Bogotá, Imprenta de "La Luz". Director Marco A. Gómez, páginas 20 y 23.

${ }^{n}$ Calvo, Gloria. Los Grandes Pedagogos en EDUCACIÓN Y CULTURA, No. 14, Revista del Centro de Estudios e Investigaciones Docentes de la Federación Colombiana de Educadores, Bogotá, Colombia, marzo de 1988, página 24.

\section{Otro texto consultado.}

Informe del Gobernador de la Provincia del Cauca a la Legislatura Provincial Constitución i Ordenanzas expedidas por ella en el año de 1853. Bogotá, imprenta del Neo-Granadino, 1854

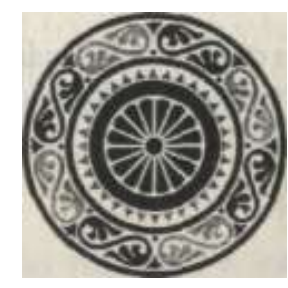

178 • Revista Historia de la Educación Colombiana 